SUPPORTING INFORMATION

\title{
Formation of Gaseous Proteins via the Ion Evaporation Model (IEM) in Electrospray Mass Spectrometry
}

Elnaz Aliyari and Lars Konermann*

Department of Chemistry, The University of Western Ontario, London, Ontario, N6A 5B7, Canada

* To whom correspondence should be addressed. E-mail: konerman@uwo.ca. 


\section{$\underline{\text { List of SI Items: }}$}

\section{Supporting Tables}

Table S1: Protonation patterns for ubiquitin simulations.

\section{Supporting Figures}

Figure S1: Ubiquitin CD spectra.

Figure S2: Ubiquitin solution charge vs. $\mathrm{pH}$.

Figure S3: MD data for ubiquitin in $3 \mathrm{~nm}$ droplets.

Figure S4: Ubiquitin mass spectra.

Figure S5: MD on ubiquitin ${ }^{12+}$.

Figure S6: Ubiquitin CRM salt adducts.

Figure S7: Salt-dependent IMS data.

Figure S8: MD data for cyt c in $5.5 \mathrm{~nm}$ droplets.

Figure S9: Orientation of ubiquitin at droplet surface.

Figure S10: Electrostatic model of IEM forces. 
Table S1. Solution phase protonation patterns of ubiquitin used for MD simulations.

\begin{tabular}{|c|c|c|c|c|c|c|c|c|c|c|c|c|c|c|c|c|c|c|c|c|c|c|c|c|c|c|}
\hline & $\begin{array}{c}\text { NT } \\
1\end{array}$ & $\begin{array}{c}K \\
6\end{array}$ & $\begin{array}{c}K \\
11\end{array}$ & $\begin{array}{c}E \\
16\end{array}$ & $\begin{array}{c}E \\
18\end{array}$ & $\begin{array}{c}D \\
21\end{array}$ & $\begin{array}{c}E \\
24\end{array}$ & $\begin{array}{l}\text { K } \\
27\end{array}$ & $\begin{array}{l}K \\
29\end{array}$ & $\begin{array}{l}\text { D } \\
32\end{array}$ & $\begin{array}{l}K \\
33\end{array}$ & $\begin{array}{c}E \\
34\end{array}$ & $\begin{array}{l}D \\
39\end{array}$ & $\begin{array}{c}R \\
42\end{array}$ & $\begin{array}{l}K \\
48\end{array}$ & $\begin{array}{c}E \\
51\end{array}$ & $\begin{array}{l}D \\
52\end{array}$ & $\begin{array}{c}R \\
54\end{array}$ & $\begin{array}{l}D \\
58\end{array}$ & $\begin{array}{l}K \\
63\end{array}$ & $\begin{array}{l}E \\
64\end{array}$ & $\begin{array}{l}\mathrm{H} \\
68\end{array}$ & $\begin{array}{l}R \\
72\end{array}$ & $\begin{array}{l}R \\
74\end{array}$ & $\begin{array}{l}\text { CT } \\
76\end{array}$ & $\begin{array}{l}\text { \# of } \\
\text { runs }\end{array}$ \\
\hline 6- & + & 0 & C & & . & 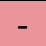 & & 0 & 0 & 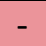 & 0 & & - & + & 0 & & - & + & & & - & 0 & + & + & 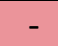 & 3 \\
\hline 6- & + & + & 0 & - & - & - & - & 0 & 0 & - & 0 & & - & + & 0 & & - & + & - & 0 & - & 0 & + & + & - & 1 \\
\hline 0 & + & + & + & - & - & - & - & + & + & - & + & - & - & + & + & - & - & + & - & + & - & 0 & + & + & - & 8 \\
\hline $6+$ & + & + & + & 0 & 0 & - & 0 & + & + & - & + & 0 & - & + & + & 0 & - & + & - & + & 0 & 0 & + & + & - & 37 \\
\hline $6+$ & + & + & + & 0 & - & - & 0 & + & + & - & + & 0 & 0 & + & + & 0 & 0 & + & - & + & - & 0 & + & + & - & 1 \\
\hline $6+$ & + & + & + & 0 & - & - & 0 & + & $T$ & - & + & 0 & 0 & + & + & 0 & - & + & - & + & 0 & 0 & + & + & - & 1 \\
\hline $7+$ & + & + & + & 0 & 0 & - & 0 & + & + & - & + & 0 & 0 & + & + & 0 & - & + & - & + & 0 & 0 & + & + & - & 2 \\
\hline $7+$ & + & + & + & 0 & 0 & 0 & 0 & + & + & - & + & 0 & - & + & + & 0 & - & + & - & + & 0 & 0 & + & + & - & 1 \\
\hline $7+$ & + & + & + & 0 & 0 & - & 0 & + & + & - & + & 0 & - & ${ }^{\top}$ & + & 0 & - & + & 0 & $T$ & 0 & 0 & + & + & - & 1 \\
\hline $8+$ & + & + & + & 0 & 0 & 0 & 0 & + & + & 0 & + & 0 & - & + & + & 0 & - & + & - & + & 0 & 0 & + & + & - & 2 \\
\hline $8+$ & + & + & + & 0 & 0 & - & 0 & + & + & 0 & + & 0 & - & + & + & 0 & 0 & + & - & $T$ & 0 & 0 & + & + & - & 1 \\
\hline $8+$ & + & + & + & 0 & 0 & - & 0 & + & + & - & + & 0 & - & + & + & 0 & 0 & + & 0 & + & 0 & 0 & + & + & - & 1 \\
\hline $8+$ & + & + & + & 0 & 0 & - & 0 & + & + & 0 & + & 0 & 0 & + & + & 0 & - & + & - & + & 0 & 0 & + & + & - & 1 \\
\hline $8+$ & + & + & + & 0 & 0 & - & 0 & + & + & 0 & + & 0 & - & + & + & 0 & - & + & 0 & + & 0 & 0 & + & + & - & 1 \\
\hline $8+$ & + & + & + & 0 & 0 & - & 0 & + & + & - & + & 0 & - & + & + & 0 & 0 & + & 0 & + & 0 & 0 & + & + & - & 1 \\
\hline $12+$ & + & + & + & 0 & 0 & 0 & 0 & + & + & 0 & + & 0 & 0 & + & + & 0 & 0 & + & 0 & + & 0 & 0 & + & + & 0 & 3 \\
\hline
\end{tabular}




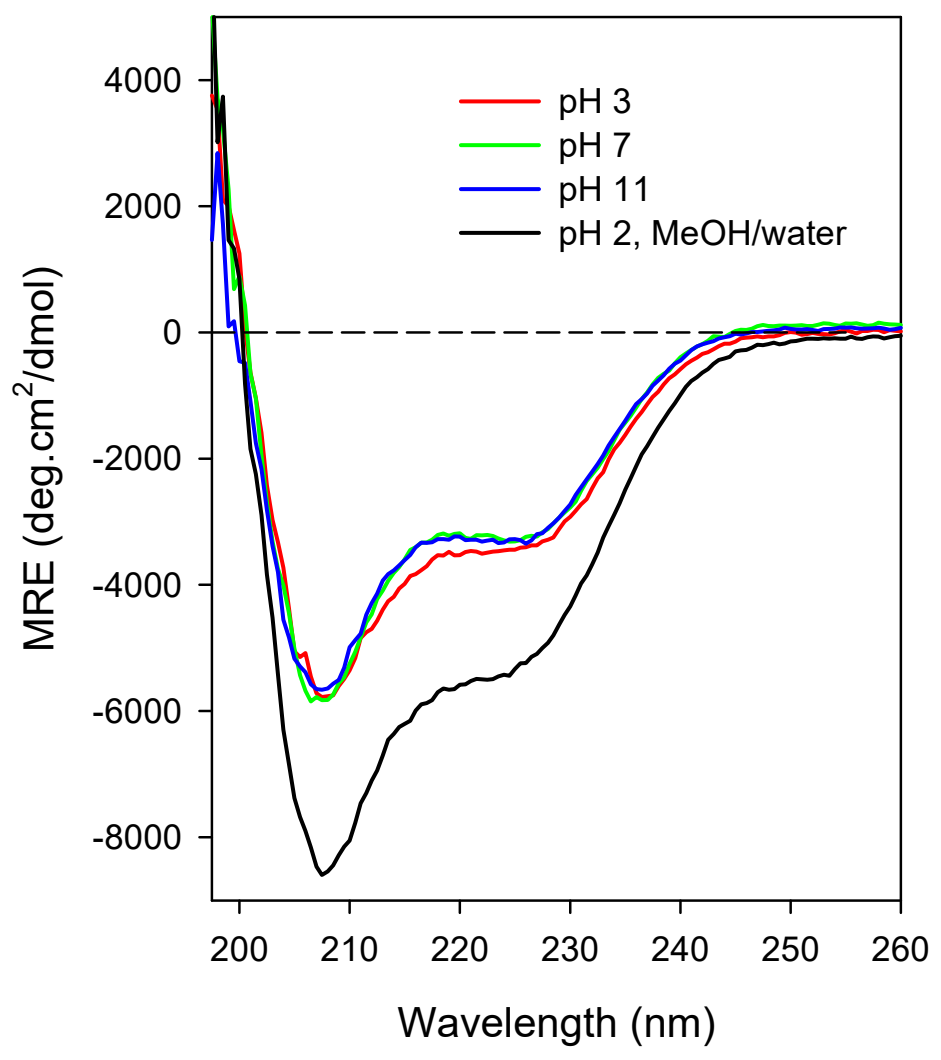

Figure S1. Circular dichroism (CD) spectra of $50 \mu \mathrm{M}$ ubiquitin in water $/ 1 \mathrm{mM} \mathrm{NaCl} / 10 \mathrm{mM}$ ammonium acetate at different $\mathrm{pH}$. All three spectra are quite similar, attesting to the fact that the native protein structure is largely unperturbed between $\mathrm{pH} 3$ and 11. For reference, a spectrum of unfolded ubiquitin is included as well (A-state, in 1:1 $\mathrm{MeOH}: \mathrm{H}_{2} \mathrm{O}, \mathrm{pH}$ 2). ${ }^{1} \mathrm{pH}$ values were adjusted using $\mathrm{HCl}$ and $\mathrm{NaOH}$ solutions. Data were acquired on a J-810 spectropolarimeter (JASCO, Easton, MD). 


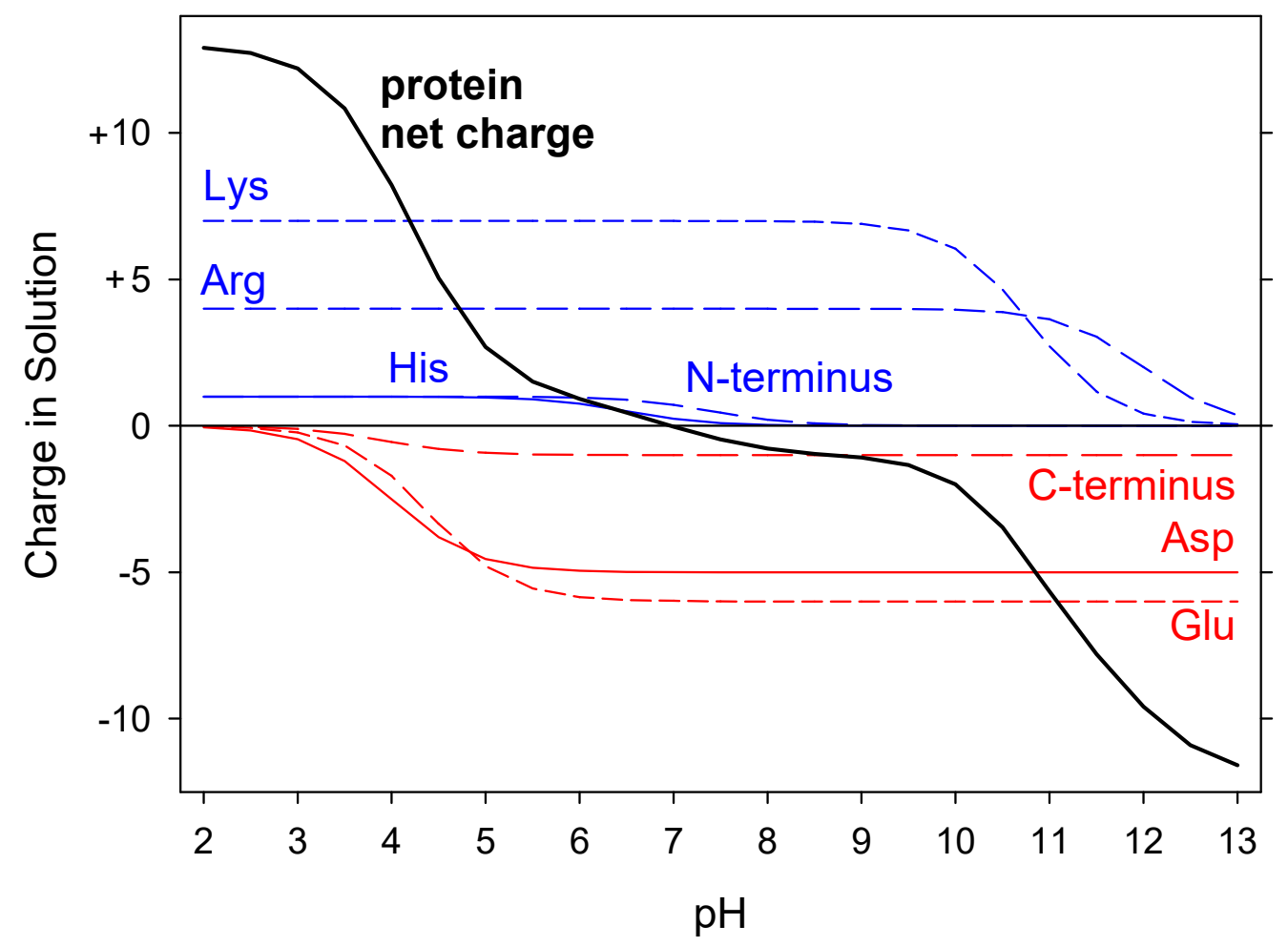

Figure S2. Ubiquitin charge in solution vs. pH (black), calculated using the HendersonHasselbalch equation. Also shown are the contributions of individual basic (blue) and acidic (red) titratable sites, weighted by their abundance in the protein. The number of sites ${ }^{2}$ and their $\mathrm{pK}_{\mathrm{a}}$ values ${ }^{3}$ are: $1 \mathrm{~N}$-terminus ${ }^{+}$(7.4); $4 \mathrm{Arg}^{+}$(12.0); $7 \mathrm{Lys}^{+}$(10.8); $1 \mathrm{His}^{+}$(6.5); $5 \mathrm{Asp} \mathrm{(4.0),} 6 \mathrm{Glu}$ (4.4), $1 \mathrm{C}$-terminus (3.9). At $\mathrm{pH} 7$ the net charge is close to zero, whereas at $\mathrm{pH} 4.4$ the protein has a $6+$ charge. 
A

\section{protein charge \\ in solution:}

$\underline{0.5 \mathrm{~ns}}$

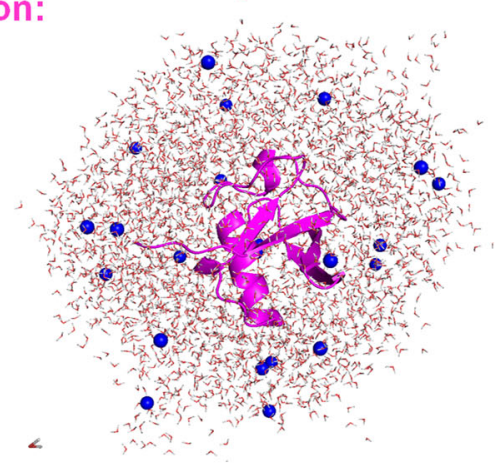

$\underline{7.5 \mathrm{~ns}}$

$\underline{17 \mathrm{~ns}}$
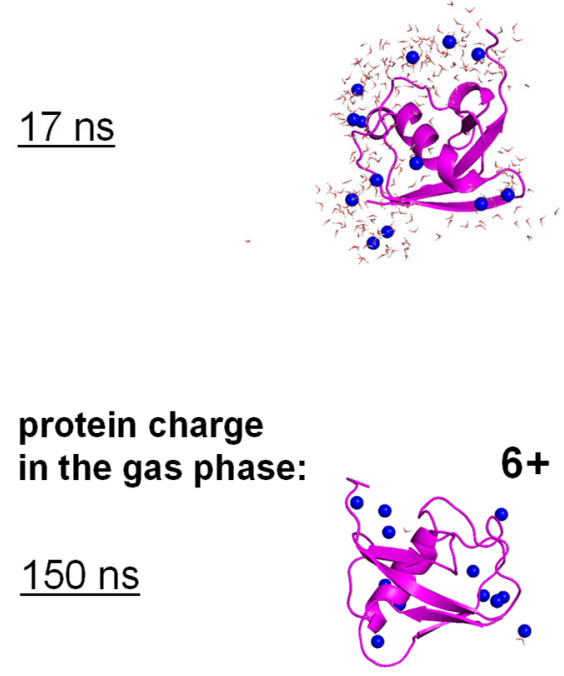

B
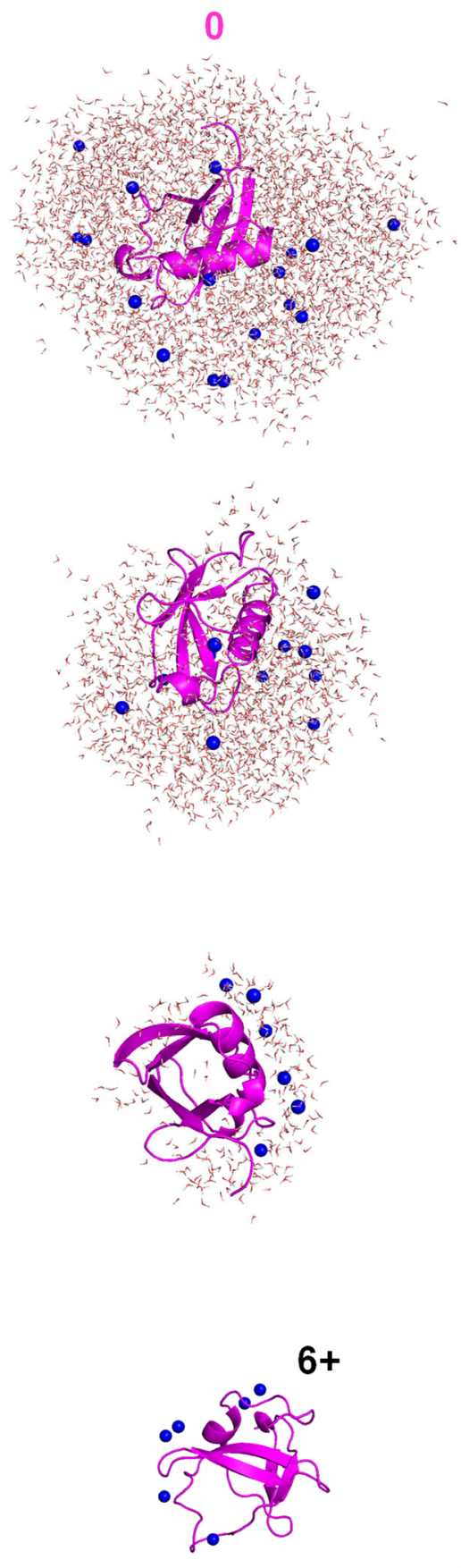

C

$6+$
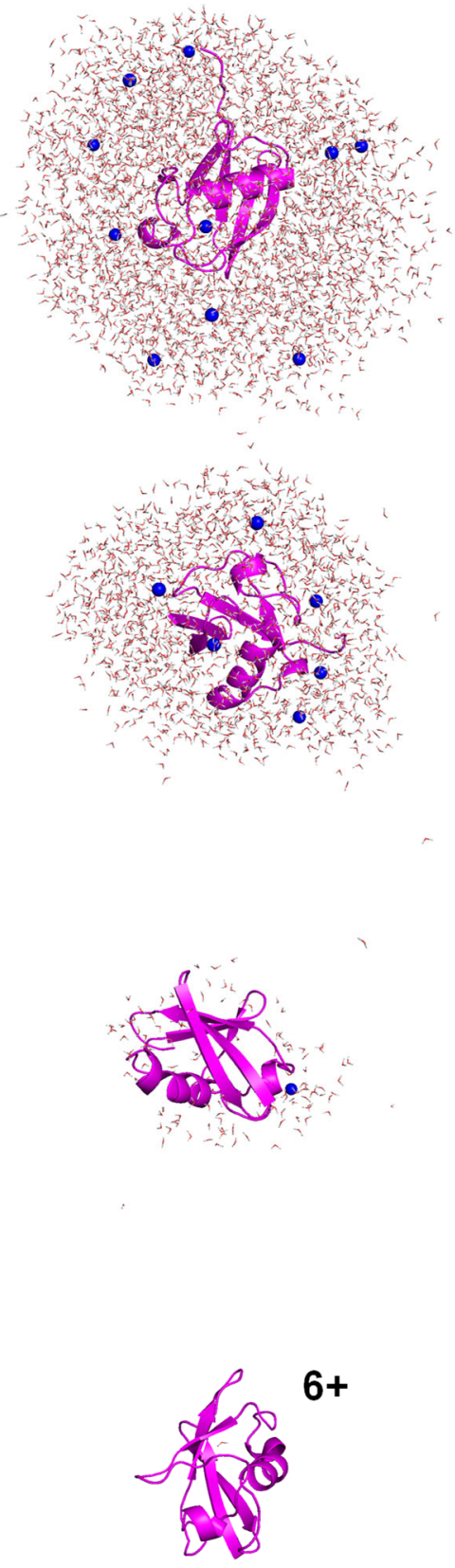

Figure S3. Examples of ESI simulations using small aqueous droplets (initial radius $3 \mathrm{~nm}$, initial droplet charge 19+). (A) Protein charge in solution =6-. (B) Protein charge in solution = zero. $(\mathrm{C})$ Protein charge in solution $=6^{+}$. In all cases $6+$ gaseous protein ions were produced via the CRM, i.e., after solvent evaporation to dryness. Coloring: protein, pink; water oxygen, red; $\mathrm{Na}^{+}$, blue. 


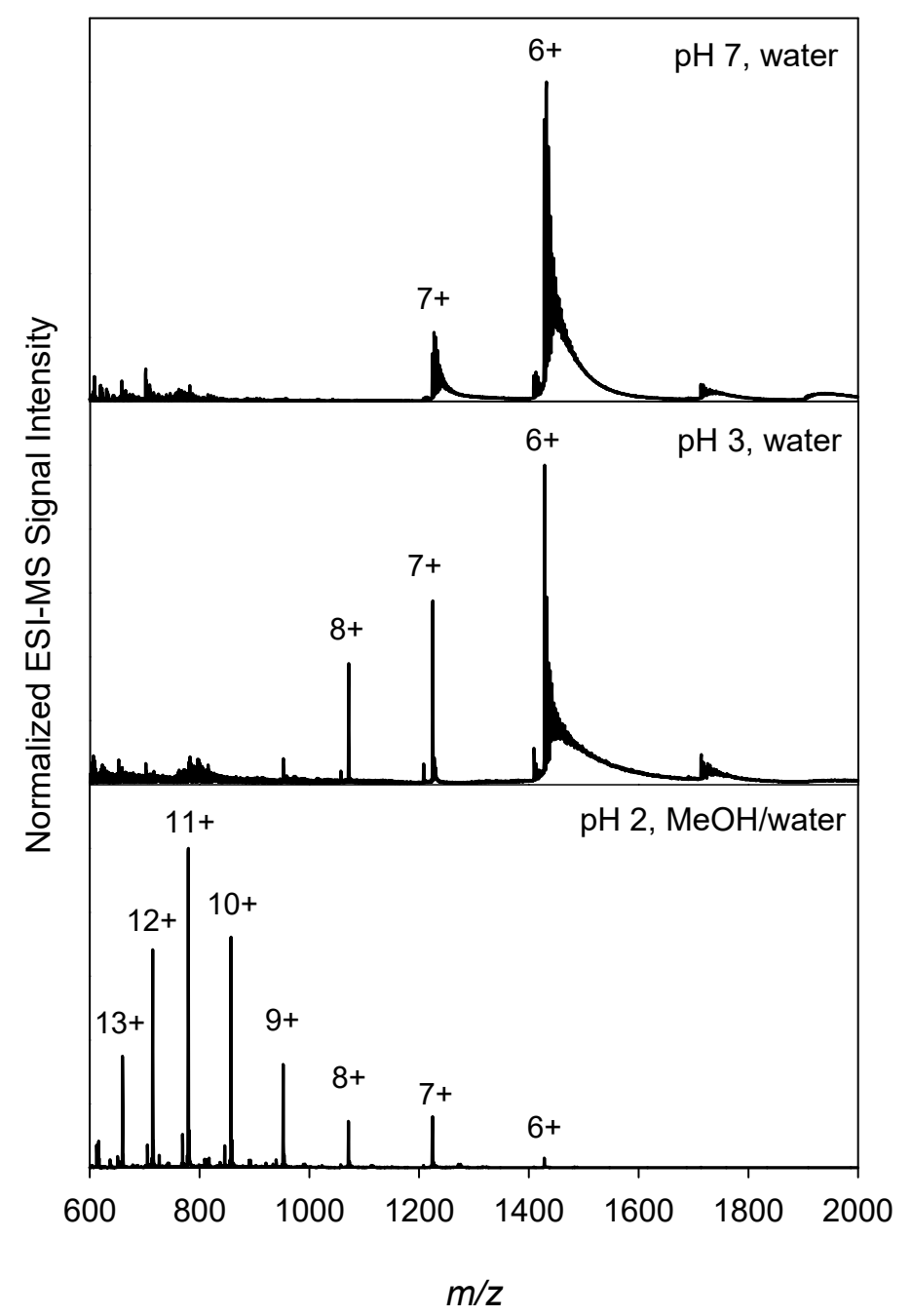

Figure S4. Comparison of ubiquitin ESI mass spectra acquired in aqueous solution containing 10 $\mathrm{mM}$ ammonium acetate and $1 \mathrm{mM} \mathrm{NaCl}$ at $\mathrm{pH} 7$ (A) and at $\mathrm{pH} 3$ (B). The low ESI charge states in panels $\mathrm{A}$ and $\mathrm{B}$ indicate a compact native structure in solution. (C) ESI mass spectrum of ubiquitin that is unfolded in solution (the so-called A-state) ${ }^{1}$ in 50/50 methanol/water at $\mathrm{pH} 2$. 

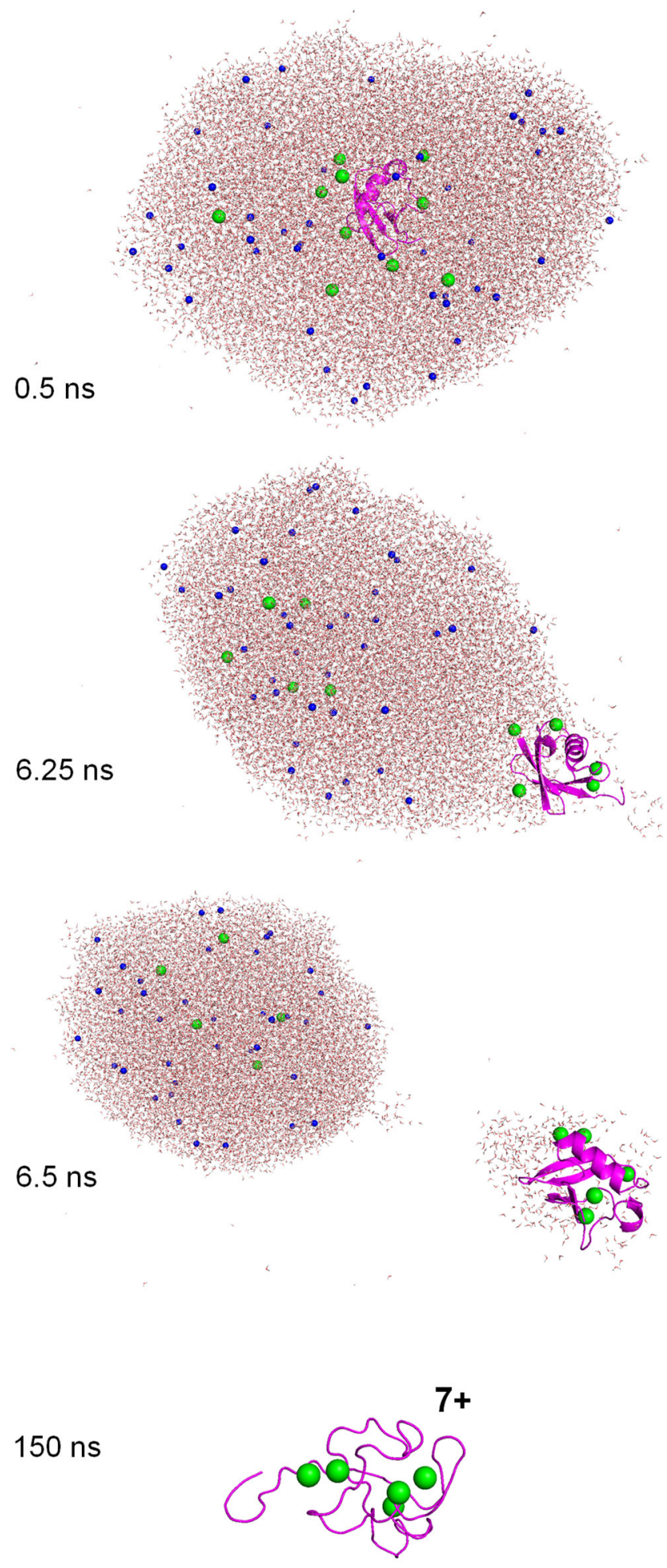

Figure S5. MD simulation data for ubiquitin in $5.5 \mathrm{~nm}$ aqueous ESI droplets, using a uiquitin ${ }^{12+}$ solution charge which corresponds to $\mathrm{pH} 3$. The initial droplet also contains 10 additional $\mathrm{NaCl}$. The IEM behavior seen here generates a $7+$ gaseous protein ion $(12+$ protein charge, with 5 bound $\mathrm{Cl}^{-}$(green)). Note that the protein is ejected in a native-like conformation (6.5 ns), but undergoes major structural changes after its solvent shell has evaporated (150 ns). 

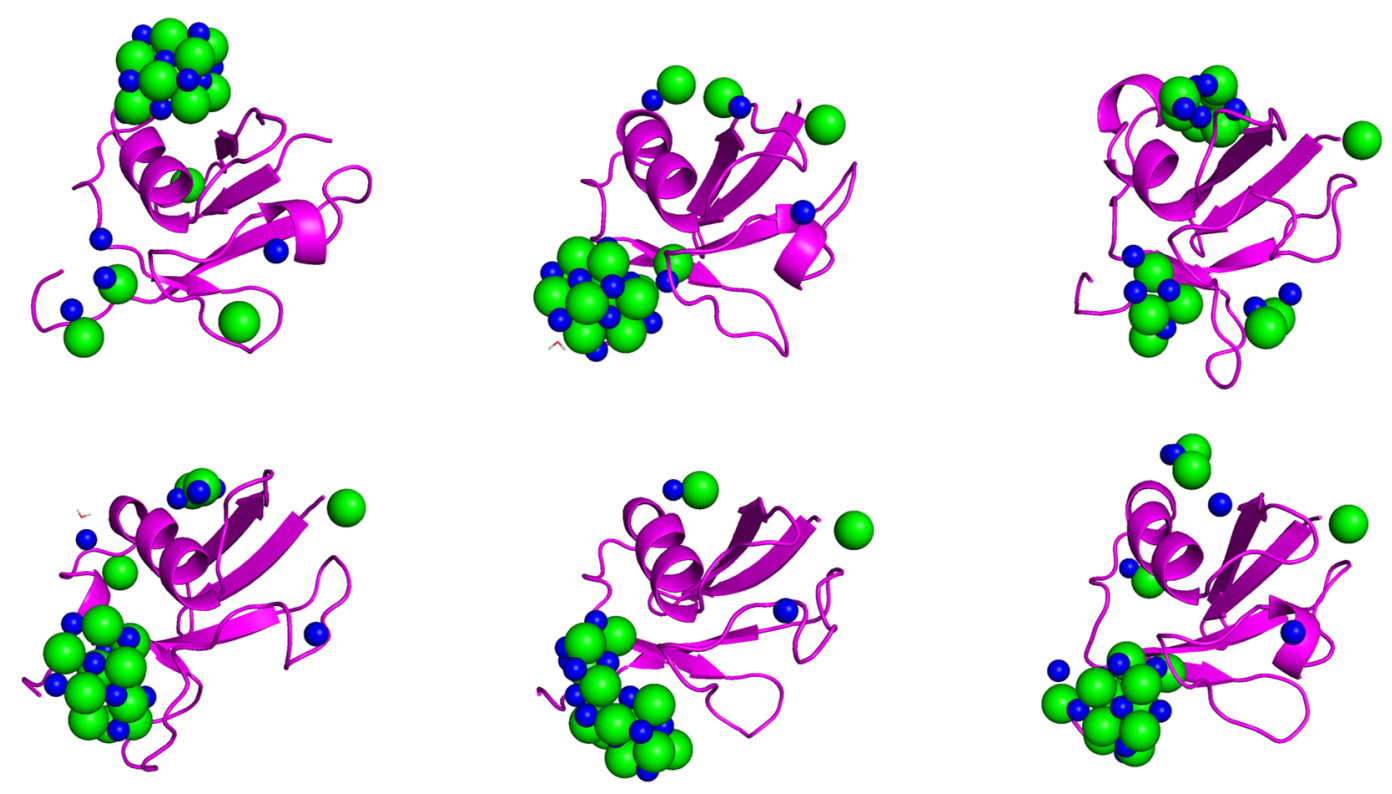

Figure S6. Examples of salt-adducted ubiquitin $6+$ ions formed via the CRM from droplets containing 15 additional $\mathrm{Na}^{+} / \mathrm{Cl}^{-}$(using starting conditions as in Figure 4A of the main text). All structures are for $t=150 \mathrm{~ns}$. The protein is shown in pink, $\mathrm{Na}^{+}$is blue, $\mathrm{Cl}^{-}$is green. 

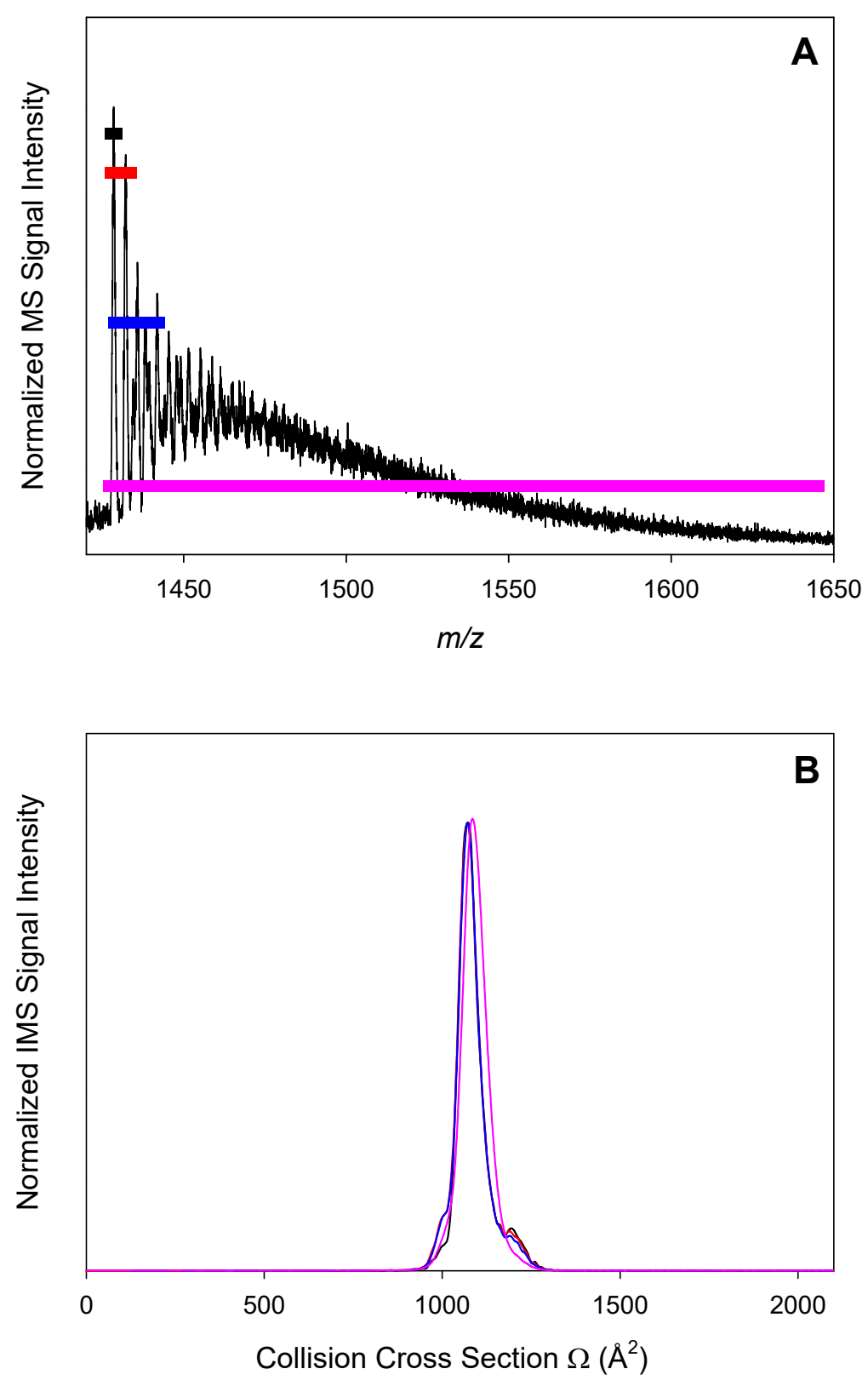

Figure S7. IMS/MS experimental data for ubiquitin electrosprayed in aqueous solution at $\mathrm{pH} 4.4$ in the presence of $1 \mathrm{mM} \mathrm{NaCl}$. (A) Expanded view of the 6+ charge state, displaying a wide range of salt adducts. Horizontal bars indicate different $\mathrm{m} / \mathrm{z}$ windows that were used for extracting the IMS data in (B). The effects of salt adduction on the measured $\Omega$ values is quite small; inclusion of all salt adducts (pink) yielded a $\Omega$ distribution that was shifted by less than $1 \%$ relative to the salt-free $[\mathrm{M}+6 \mathrm{H}]^{6+}$ ions (black). 

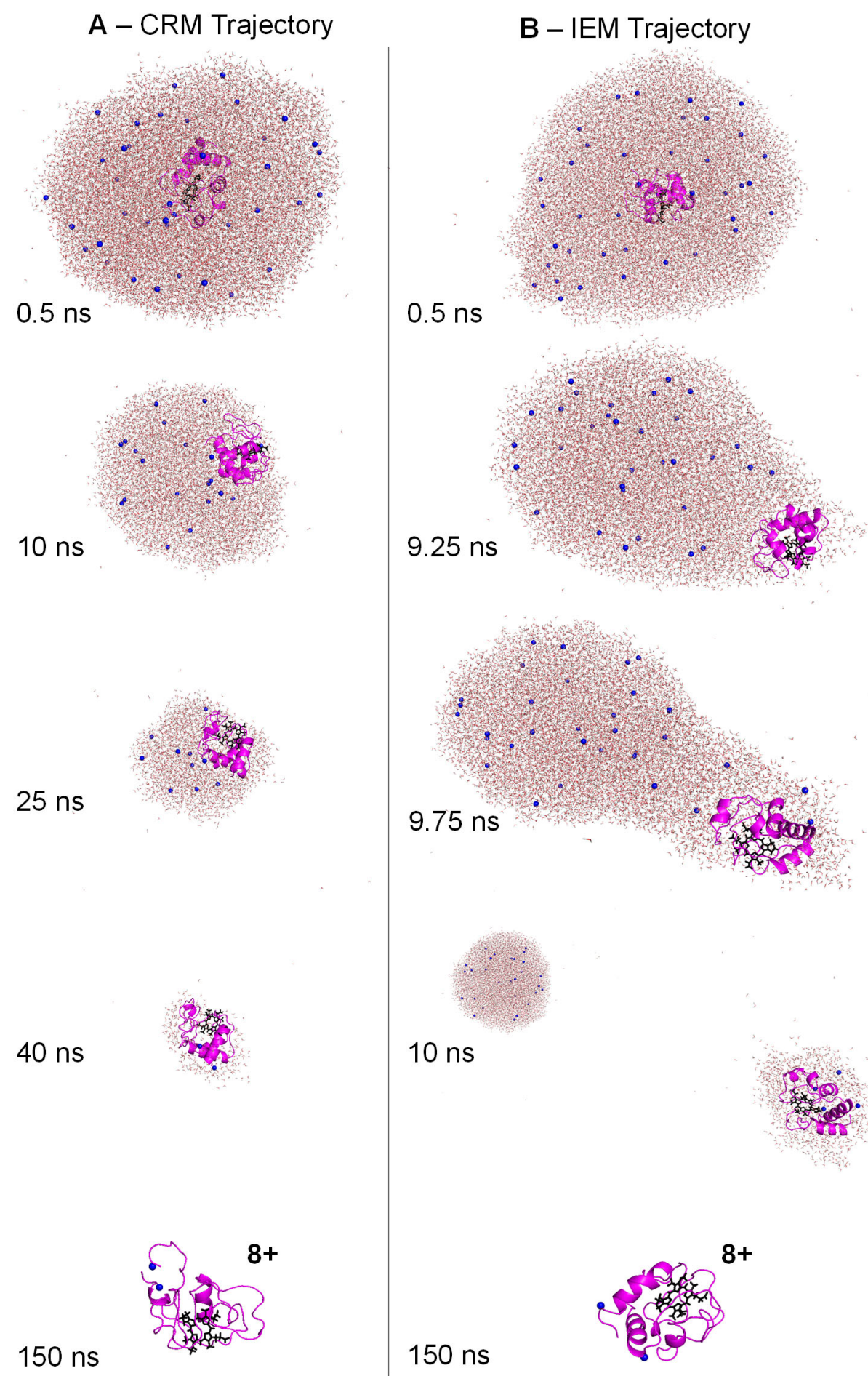

$10 \mathrm{~ns}$

150 ns

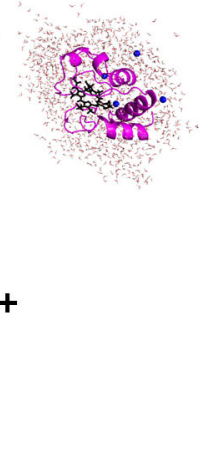

Figure S8. MD simulations for cytochrome $c$ (cyt $c$ ) in $5.5 \mathrm{~nm}$ aqueous ESI droplets, using a $6+$ solution charge for the protein which corresponds to $\mathrm{pH}$ 7. (A) CRM trajectory, (B) IEM trajectory. Gaseous protein ions formed after 150 ns have a $8+$ charge due to binding of $2 \mathrm{Na}^{+}$. This charge state is consistent with native ESI mass spectra. ${ }^{4}$ The data shown here were generated in the absence of $\mathrm{NaCl}$. In total, 14 cyt $c^{6+}$ simulations with and without salt were performed in $5.5 \mathrm{~nm}$ droplets, yielding 9 CRM runs and 5 IEM runs. Simulations on cyt $c^{8+}$ in $5.5 \mathrm{~nm}$ droplets yielded 3/4 IEM runs and 1/4 CRM runs; for cyt $c^{6-} 3 / 3$ runs showed CRM behavior. MD simulations in 3 $\mathrm{nm}$ droplet all followed the CRM, regardless of the protein charge in solution. These observations are consistent with the ubiquitin data discussed in the main text. 

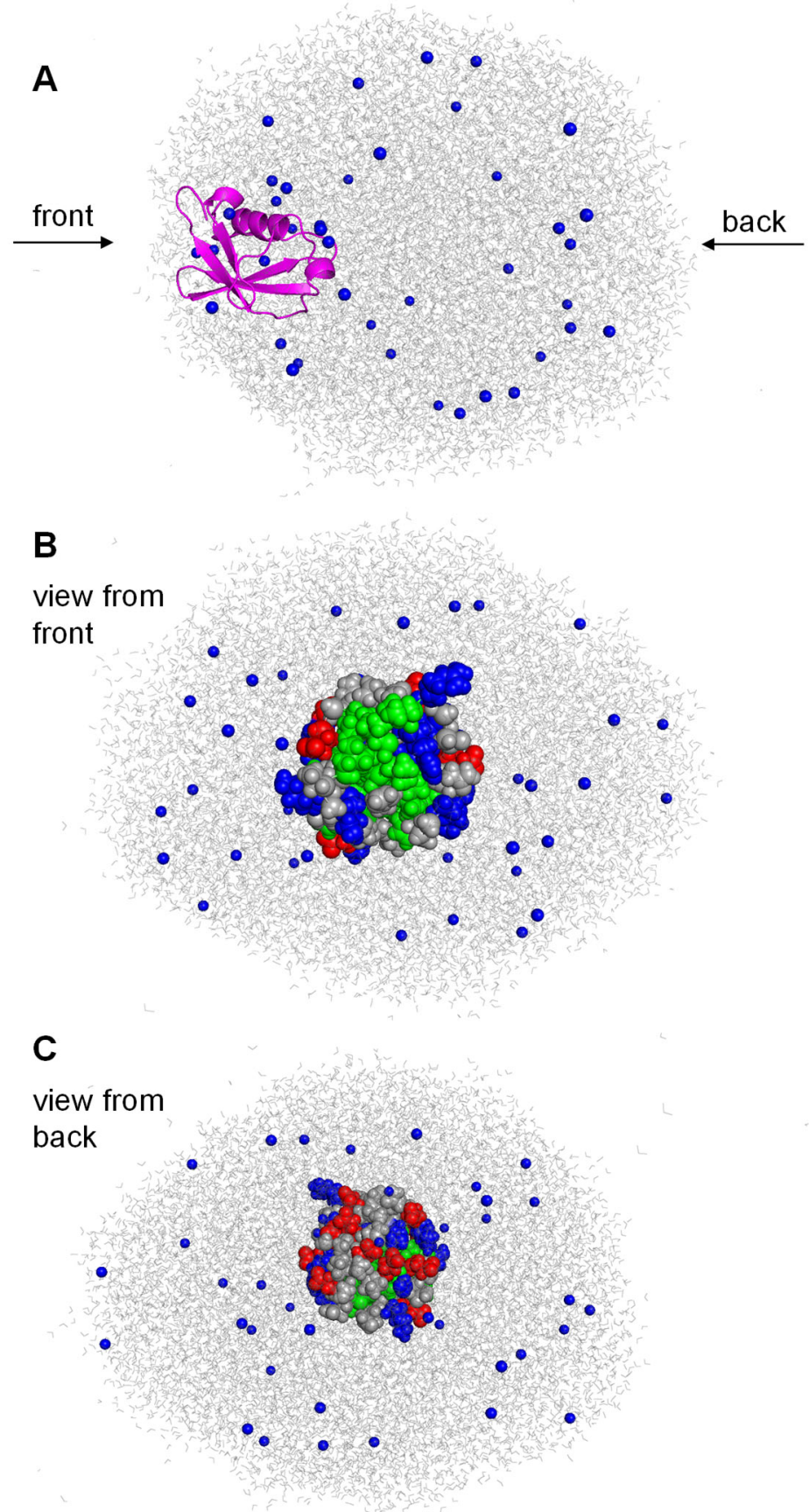

Figure S9. CRM trajectory of ubiquitin ${ }^{6-}$ in a $5.5 \mathrm{~nm}$ droplet at $t=13.8 \mathrm{~ns}$ (same frame as in Figure $3 \mathrm{~A}$ of the main text). (A) Preferred protein orientation at the droplet surface. (B) Droplet rotated by $90^{\circ}$, highlighting the presence of a hydrophobic patch (green) that points toward the vapor phase. (C) Droplet rotated by $-90^{\circ}$, illustrating highly hydrophilic side chains (acidic-red, basic-blue) that point toward the droplet interior where they are extensively solvated. Green: Leu/Ile/Val/Phe. Blue: N-terminus/Arg/Lys. Red: Asp/Glu/C-terminus. All other residues are shown in gray. 

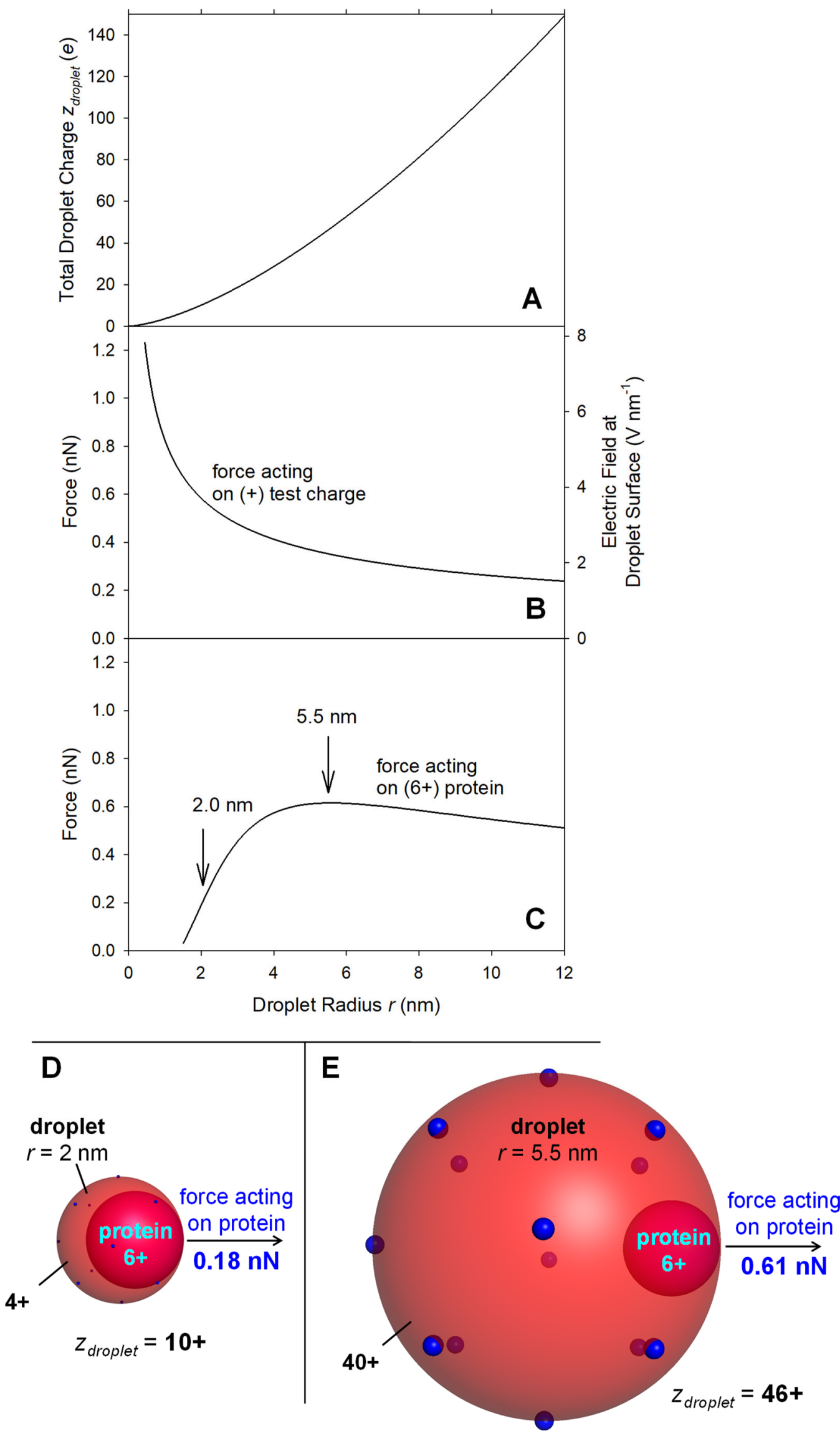
Figure S10 (previous page). Simplistic model to estimate the force acting on ubiquitin ${ }^{6+}$ that has migrated to the surface of a Rayleigh-charged water droplet with radius $r$. (A) Total droplet charge at the Rayleigh limit, $z_{\text {droplet }}=8 \pi / e \times\left(\varepsilon_{0} \gamma r^{3}\right)^{1 / 2}$ with $\gamma=0.05891 \mathrm{~N} \mathrm{~m}^{-1} .^{5}$ (B) Repulsive force acting on a $+e$ point charge at the droplet suface, calculated as force $=E \times e$, where the electric field is ${ }^{6} E=2(\gamma / \varepsilon o r)^{1 / 2}$. (C) Force that tends to push the protein out of the droplet. The force is largest for droplets with radius $\sim 5.5 \mathrm{~nm}$, implying that this droplet size that is most likely to cause protein IEM. For smaller droplets protein IEM becomes less likely because the force diminishes. This explains why in $5.5 \mathrm{~nm}$ droplets can cause IEM ejection of ubiquitin ${ }^{6+}$ (Figure 3C), while smaller droplets show CRM behavior (Figure S3C). (D) $2 \mathrm{~nm}$ aqueous droplet, total droplet charge $10+$. The protein is shown as a sphere with $1.5 \mathrm{~nm}$ radius, calculated from the ubiquitin mass of $8565 \mathrm{Da}$ and a $1 \mathrm{~g} \mathrm{~cm}^{-3}$ density. ${ }^{7}$ Repulsion between the protein $(6+)$ and the remaining droplet charges $(4+)$ results in a force of $0.18 \mathrm{nN}$. (E) Same as in panel D, but for a 5.5 $\mathrm{nm}(46+)$ droplet. Repulsion between the protein $(6+)$ and the remaining droplet charges $(40+)$ results in a much larger force of $0.61 \mathrm{nN}$, thereby promoting protein IEM. The fractional nonprotein droplet charge was spread evenly over 13 points on the droplet surface (blue spheres in panels $\mathrm{D} / \mathrm{E}$ ), skipping the point where the protein touches the surface. Electrostatic calculations were performed in Python. 


\section{SI References}

(1) Brutscher, B.; Brüwchweiler, R.; Ernst, R. R. Backbone Dynamics and Structural Characterization of the Partially Folded A State of Ubiquitin by $1 \mathrm{H}, 13 \mathrm{C}$ and $15 \mathrm{~N}$ Nuclear Magnetic Resonance Spectroscopy. Biochemistry 1997, 36, 13043-13053.

(2) Vijay-Kumar, S.; Bugg, C. E.; Cook, W. J. Structure of Ubiquitin Refined at 1.8 A Resolution. J. Mol. Biol. 1987, 194, 531-544.

(3) Creighton, T. E. Proteins; W. H. Freeman \& Co: New York, 1993.

(4) McAllister, R. G.; Metwally, H.; Sun, Y.; Konermann, L. Release of Native-Like Gaseous Proteins from Electrospray Droplets via The Charged Residue Mechanism: Insights from Molecular Dynamics Simulations. J. Am. Chem. Soc. 2015, 137, 12667-12676.

(5) Lide, D. R. CRC Handbook of Chemistry and Physics, 82nd ed.; CRC Press: Boca Raton, London, New York, Washington, 2001.

(6) Konermann, L.; Rodriguez, A. D.; Liu, J. On the Formation of Highly Charged Gaseous Ions from Unfolded Proteins by Electrospray Ionization. Anal. Chem. 2012, 84, 67986804.

(7) de la Mora, J. F. Electrospray Ionization of large multiply charged species proceeds via Dole's charged residue mechanism. Anal. Chim. Acta 2000, 406, 93-104. 